\title{
A Parieto-Medial Temporal Pathway for the Strategic Control over Working Memory Biases in Human Visual Attention
}

\author{
David Soto, ${ }^{1}$ Ciara M. Greene, ${ }^{1}$ Anastasia Kiyonaga, ${ }^{2}$ Clive R. Rosenthal, ${ }^{3}$ and Tobias Egner ${ }^{2}$ \\ ${ }^{1}$ Division of Brain Sciences, Imperial College London, London W6 8RP, United Kingdom, ${ }^{2}$ Department of Psychology and Neuroscience and Center for \\ Cognitive Neuroscience, Duke University, Durham, North Carolina 27708 and ${ }^{3}$ Nuffield Department of Clinical Neurosciences, University of Oxford, Oxford \\ OX3 9D2, United Kingdom
}

\begin{abstract}
The contents of working memory (WM) can both aid and disrupt the goal-directed allocation of visual attention. WM benefits attention when its contents overlap with goal-relevant stimulus features, but WM leads attention astray when its contents match features of currently irrelevant stimuli. Recent behavioral data have documented that WM biases of attention may be subject to strategic cognitive control processes whereby subjects are able to either enhance or inhibit the influence of WM contents on attention. However, the neural mechanisms supporting cognitive control over WM biases on attention are presently unknown. Here, we characterize these mechanisms by combining human functional magnetic resonance imaging with a task that independently manipulates the relationship between WM cues and attention targets during visual search (with WM contents matching either search targets or distracters), as well as the predictability of this relationship (100 vs 50\% predictability) to assess participants' ability to strategically enhance or inhibit WM biases on attention when WM contents reliably matched targets or distracter stimuli, respectively. We show that cues signaling predictable ( $>$ unpredictable) WM-attention relations reliably enhanced search performance, and that this strategic modulation of the interplay between WM contents and visual attention was mediated by a neuroanatomical network involving the posterior parietal cortex, the posterior cingulate, and medial temporal lobe structures, with responses in the hippocampus proper correlating with behavioral measures of strategic control of WM biases. Thus, we delineate a novel parieto-medial temporal pathway implementing cognitive control over WM biases to optimize goal-directed selection.
\end{abstract}

\section{Introduction}

One important function of working memory (WM) is for its contents to guide the deployment of attention based on internal goals. Attention can also be involuntarily biased by task-irrelevant, WM-matching stimuli, suggesting an obligatory coupling between WM and attention (Soto et al., 2008; Olivers et al., 2011). Recent studies suggest that these involuntary WM biases may nevertheless be subject to strategic control (Han and Kim, 2009; Carlisle and Woodman, 2011; Kiyonaga et al., 2012). WM biases over visual selection can at times be weak or abolished (Downing and Dodds, 2004; Houtkamp and Roelfsema, 2006; Woodman and Luck, 2007; Peters et al., 2009). WM's hold over attention therefore appears to be flexible and goal-dependent.

The present functional magnetic resonance imaging (fMRI) study was designed to elucidate the neural mechanisms underlying strategic control over WM biases of attention, namely (1) the

Received June 1, 2012; revised 0ct. 4, 2012; accepted 0ct. 8, 2012.

Author contributions: D.S. and T.E. designed research; D.S., C.M.G., A.K., and C.R.R. performed research; D.S., C.M.G., and T.E. analyzed data; D.S., C.M.G., C.R.R., and T.E. wrote the paper.

This work was supported by National Institute of Mental Health Award R01MH087610 to T.E. and by a grant from the Medical Research Council (U.K., 89631) to D.S

The authors declare no conflict of interest.

Correspondence should be addressed to Dr. David Soto at the above address. E-mail: d.soto@imperial.ac.uk.

DOI:10.1523/JNEUROSCI.2647-12.2012

Copyright $\odot 2012$ the authors $\quad 0270-6474 / 12 / 3217563-09 \$ 15.00 / 0$ intentional use of a WM cue for directing attention toward a matching target, and (2) the controlled inhibition of an irrelevant WM cue to avoid attentional capture by matching distracters. To this end, we modified a well established experimental protocol for assessing the involuntary coupling between WM and attention (Soto et al., 2008). The canonical finding is that visual search for a target object is impaired by the presence of a distracter item in the search array that matches the contents of WM (Soto et al., 2005), even when observers know that the contents of WM will never aid search. Here we compared behavioral performance and neural responses when WM cues were either always invalid or always valid with a condition where valid and invalid cue trials were equally likely, providing observers with little incentive to control the WM bias on attention; in contrast, when WM cues were either always invalid or always valid, subjects could optimize search by intentionally enhancing or inhibiting the WM bias.

First, we isolated anticipatory components for enhancement/ inhibition of WM biases by comparing their neural signature during cue-only trials (where the WM cues were not followed by search displays). Second, we investigated the consequences of these control operations on the search process itself. Prior evidence implicates the posterior parietal cortex (PPC) in developing attentional sets for relevant target features (Toth and Assad, 2002; Egner et al., 2008; Schenkluhn et al., 2008), indicating a prime candidate for the WM modulation of attention when the 
WM contents are known to be relevant. By contrast, the neural substrate for inhibiting the influence of irrelevant WM contents on attention has, to our knowledge, not been previously investigated. One possibility is that frontoparietal regions involved in selection of goal-relevant information (Corbetta and Shulman, 2002) may also be critical for controlling irrelevant WM biases. A plausible alternative substrate for this process could involve regions in the medial temporal lobe complex that have been shown to be sensitive to the presence of items matching the contents of WM (Chelazzi et al., 1993; Soto et al., 2007; Duncan et al., 2009; Dudukovic et al., 2011; Greene and Soto, 2012).

\section{Materials and Methods}

Participants. Twenty-one healthy observers (eight females; age range, 22-34 years) who provided written informed consent took part in the

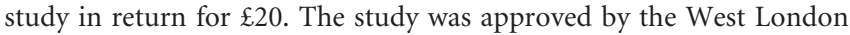
Research Ethics Committee.

Experimental protocol. The task was programmed and controlled using E-prime (Version 2.0; Psychology Software Tools). Each trial began with a fixation display for $500 \mathrm{~ms}$ that was followed by a memory cue for 250 ms (see Fig. 1A). The WM cue was a colored circle drawn in one of four different colors selected at random (see below). Extinction of the cue was followed by a delay period of $2 \mathrm{~s}$. The search display then appeared for 100 $\mathrm{ms}$ and was composed of three colored circles at the corners of an imaginary triangle. Each circle contained a line; two of the lines were vertical while the target line was tilted $16^{\circ}$ either to the left or right. The participants' task was to indicate the orientation of the tilted line via button press during a time window of $1000 \mathrm{~ms}$. Target location and orientation were randomly selected on a trial-by-trial basis. The memory and search circles were randomly selected from one of four colors (red, blue, green, or yellow). Each circle was a color singleton in the search display. WM cues could be "valid" or "invalid," depending on whether the memory cue surrounded the search target or a search distracter, respectively. Valid and invalid conditions were blocked leading to blocks where the cue was (1) always valid (valid blocks), (2) always invalid (invalid blocks), or (3) equally likely to be valid or invalid (50/50 blocks).

As in previous studies using this protocol (Soto et al., 2007), we ensured that participants held the cues in memory throughout the trials by using memory "catch" trials (18.5\%) where a memory probe was presented for $2 \mathrm{~s}$ instead of the visual search display. The probe consisted of a colored circle, and participants had to provide a match/mismatch response, indicating whether or not the probe was the same color as the memory cue. To estimate BOLD responses associated with the processing of the WM cue alone (i.e., cue delay period activity), we also included $22.2 \%$ of "cue-only" trials per block where the memory cue was not followed by a search display (Ollinger et al., 2001). Here the cue was followed by the usual $2 \mathrm{~s}$ delay plus the intertrial time interval (ITI). Participants were given appropriate training instructions outside the scanner and also received a $10 \mathrm{~s}$ instruction display at the beginning of each scanning block to inform them about the nature of cue predictability. Participants received clear instructions on the presence of cue-only trials and memory "catch" trials. The ITI was jittered between 2.5 and $4.5 \mathrm{~s}$, with a pseudo-exponential distribution ( $48 \%$ of ITIs were $2.5 \mathrm{~s}$, $22.2 \%$ of ITIs were $3 \mathrm{~s}, 11.1 \%$ were $3.5 \mathrm{~s}, 7.4 \%$ were $4 \mathrm{~s}$, and $7.4 \%$ were $4.5 \mathrm{~s}$ ), to facilitate the independent estimation of BOLD responses across trials (Ollinger et al., 2001).

The task was divided into three runs. Each run was composed of 4 blocks of 27 trials each, including 5 memory-catch trials and 6 cue-only trials. The remaining 16 trials per block were either $100 \%$ valid or invalid on highly predictable valid and invalid blocks, or half (8) valid and half invalid on unpredictable 50/50 blocks. The order of blocks within a run was selected randomly.

Participants completed several practice sessions outside the scanner, initially with a visual search display duration of $500 \mathrm{~ms}$ followed by a search display duration of $100 \mathrm{~ms}$ until performance was above $90 \%$ correct. They were told to avoid eye movements during the search, and we used the very brief search display time $(100 \mathrm{~ms})$ to further discourage eye movements.
Image acquisition/scanning parameters. MRI scanning was conducted using a Siemens Magnetom Verio 3T MRI scanner and a 32-channel head coil. Following a brief localizer scan to determine the orientation of the subject's head within the field, $176 \mathrm{~T} 1$ weighted anatomical sagittal images were acquired with an field of view (FOV) of $220 \times 220 \mathrm{~mm}$, repetition time (TR) of $1900 \mathrm{~ms}$, echo time (TE) of $2.48 \mathrm{~ms}$, and slice thickness of $1 \mathrm{~mm}$, leading to a voxel resolution of $1 \times 1 \times 1 \mathrm{~mm}$. Three functional runs of $2^{*}$ weighted echo planar imaging were conducted to obtain 38 contiguous sagittal slices covering the whole brain. Each run contained 367 volumes that were acquired with an FOV of $222 \times 222$ $\mathrm{mm}$, TR of $2200 \mathrm{~ms}$, TE of $30 \mathrm{~ms}$, and slice thickness of $3 \mathrm{~mm}$. The resulting voxel resolution was $2.4 \times 2.4 \times 3.0 \mathrm{~mm}$.

Imaging data analysis. fMRI data processing was carried out using FEAT (fMRI Expert Analysis Tool) Version 5.98, part of Functional Magnetic Imaging of the Brain (FMRIB) Software Library (FSL) (www.fmrib. ox.ac.uk/fsl). The first six volumes of the echo-planar imaging (EPI) scan were removed from each scanning session to account for T1 equilibrium effects, leaving 361 scans per run. The following pre-statistics processing was applied: non-brain removal using Brain Extraction Tool (Smith, 2002); motion correction using MCFLIRT (Motion Correction using FMRIB's Linear Image Registration Tool) (Jenkinson et al., 2002); $150 \mathrm{~s}$ high-pass temporal filtering and spatial smoothing using a Gaussian kernel of FWHM $6.0 \mathrm{~mm}$; and time-series statistical analysis carried out using FILM (FMRIB's Improved Linear Model) with local autocorrelation correction (Woolrich et al., 2001) for each individual run. The different trial types were modeled from the onset of the memory cue and each event had $2.35 \mathrm{~s}$ duration (including cue exposure, cue-search delay, and search exposure time) as boxcar functions convolved with the hemodynamic response function. Explanatory variables (EVs) included the onset times for valid and invalid trials separately for the 100 and $50 \%$ probability of validity (four EVs), and the onset times of cue-only trials in the context of $100 \%$ valid, $100 \%$ invalid, and $50 / 50$ blocks (three EVs). Additional regressors of no interest included memory catch trials, errors, and the motion realignment parameters. The temporal derivative of the hemodynamic response function was also added to the model for each EV to account for latency differences between slice acquisitions. Subsequently, we performed cross-run individual analyses using fixed effects to derive $Z$ statistic images for all conditions and thereafter performed group-level analyses using FLAME (FMRIB's Local Analysis of Mixed Effects) stage $1+2$ as implemented in FEAT. We report maps of BOLD responses thresholded using clusters determined by a voxelwise $Z$ threshold of 2.3 and a corrected cluster significance threshold of $p=0.05$, unless otherwise noted. Each individual's EPI scans were registered to high-resolution structural images using FLIRT and then coregistered and transformed to standard (Montreal Neurological Institute, MNI) space. The location of the activations was based on the Jülich histological atlas within FSL.

\section{Results}

\section{Behavioral results}

Due to a technical problem, behavioral responses in 2 of the 21 participants were not recorded. Data from the remaining participants were entered in the analyses. Memory performance on catch trials was very high (invalid blocks $=93 \% ; 50 / 50$ blocks $=$ 95.7\%; valid blocks $=95 \%$ ) and did not differ across blocks $\left(F_{(2,36)}=1.44, p=0.25\right)$. These data confirm that participants encoded and maintained the WM cues as instructed. Median reaction times (RTs) of trials with correct responses in the search task were entered into a 2 (trial type: valid, invalid) $\times 2$ (predictability: high [100\% valid/invalid], low [50/50 valid/invalid]) repeated-measures ANOVA. In line with previous studies, we observed a main effect of trial type $\left(F_{(1,18)}=81.65, p<0.0001\right)$ with faster performance on valid trials relative to invalid trials There was also a main effect of predictability $\left(F_{(1,18)}=14.25, p<\right.$ 0.001 ), with faster performance when participants expected the WM cue to be either valid or invalid throughout the block relative to the low predictability condition. This pattern of results is de- 


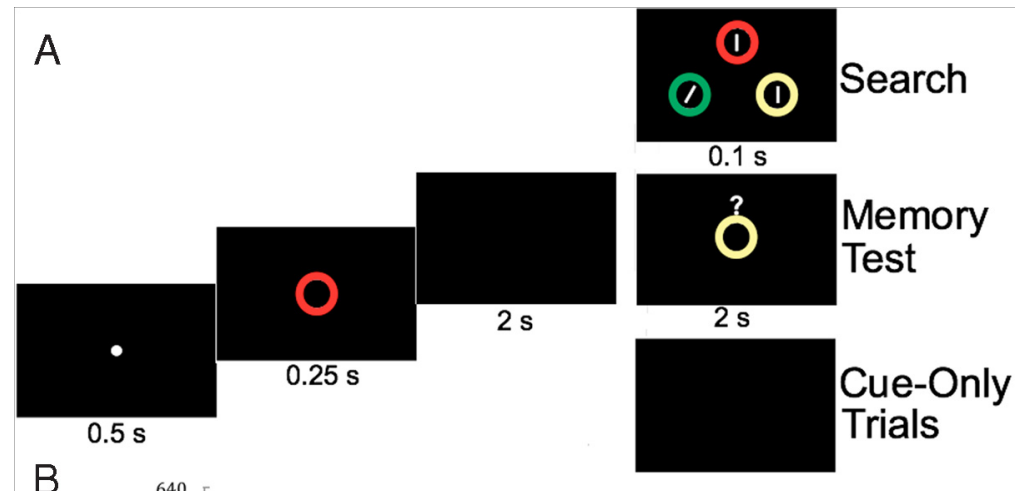

B

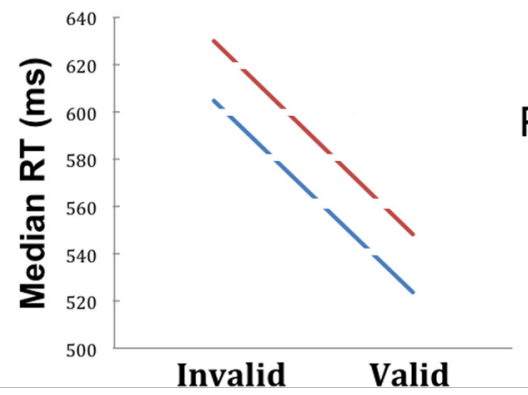

Figure 1. Experimental protocol and behavioral results. $\boldsymbol{A}$, Illustration of the timing and sequence of events within an example trial. Each trial consisted of a fixation period followed by a memory cue, then by a cue-to-probe interval, and finally by either a visual search display (on standard search trials), a memory probe (on memory catch trials), or no display (on cue-only trials). Trials were separated by a jittered intertrial interval (data not shown, see Materials and Methods, Experimental protocol). In the example trial displayed here, the WM cue would be considered an invalid cue for the visual search, because the WM cue surrounds a search distracter (the search target is the tilted bar). $\boldsymbol{B}$, Median search response time is plotted as a function of WM cue validity and whether the cue validity was predictable.

picted in Figure $1 B$. Trial and block type factors did not interact $(F<1, p=0.94)$.

The search accuracy results replicated the general pattern of the RT data. There was a main effect of trial type $\left(F_{(2,18)}=16.09\right.$, $p<0.001)$ with better performance on valid than on invalid trials, and there was a nonsignificant trend for higher search accuracy on valid/invalid relative to $50 / 50$ blocks $\left(F_{(2,18)}=2.57\right.$, $p>0.126)$ and no interaction between factors $(F<1, p>0.33)$. Note that validity effects were unlikely to stem from participants confounding the search task with the memory catch trials, as the two display types were perceptually highly dissimilar (see Fig. $1 A$ ). It can also be ruled out that validity effects were driven by participants preparing for possible memory retrieval probes, as these probes were relatively rare and, more importantly, occurred with equal frequency across conditions, such that any effects of retrieval expectation would be orthogonal to our experimental factors of interest.

In sum, the behavioral results demonstrate that: (1) participants encoded and maintained the cue stimuli in WM; (2) valid, target-matching WM cues enhanced search performance relative to invalid, distracter-matching cues; and (3) the degree to which WM cues affected search performance was partly under the subjects' control, as search RTs were faster when the validity of the WM cue was known a priori. Specifically, subjects managed to exploit the predictability of the WM-attention relationship by enhancing the influence of the WM cue on the search process in $100 \%$ valid blocks and inhibiting that influence in $100 \%$ invalid blocks relative to unpredictable (50/50) blocks.

\section{fMRI results}

Our main goal was to delineate the neural regions associated with cognitive control over WM biases. Before exploring these effects of predictability, however, we first investigated the effects of WM validity per se. Main effects of validity of the WM cue during search were found in the parahippocampal gyrus (MNI: $-12,-4,-26 ; 936$ voxels), which showed enhanced bilateral responses during valid trials relative to invalid trials (Valid $>$ Invalid contrast, collapsed across $100 \%$ and 50/50 conditions) (Fig. 2A). Frontoparietal regions, on the other hand, were associated with increased BOLD response on invalid trials relative to valid trials (Fig. $2 B$ ). Specifically, invalid as compared to valid trials were associated with activity in a large, bilateral cluster in posterior parietal cortex (BA7) (MNI: - 16, -60, 44, 971 voxels in the right hemisphere; $\mathrm{MNI}: 16,-76,54$, 4139 voxels in the right hemisphere) comprising superior regions and also more inferior ventral regions around the angular gyrus in the vicinity of the temporoparietal junction. We also observed a cluster of activation in the right inferior frontal gyrus (BA48) (MNI: 50, -2, 14, 817 voxels). These results broadly replicate previous research (Corbetta and Shulman, 2002), and the involvement of these frontoparietal regions may reflect their well documented role in attentional capture (here driven by WM-matching distracters) and the reorienting of attention toward the sought-after target (Corbetta and Shulman, 2002). As part of the same cluster, we found activations in the right thalamus, including the pulvinar (MNI: 22, -28, 10) and the lateral thalamus (MNI: 14, -18, 14), which have previously been implicated in WM biases of attention (Soto et al., 2007, 2012a; Grecucci et al., 2010), the filtering of distracters during search (Strumpf et al., 2012), and goal-based inhibition of irrelevant WM-matching contents (Rotshtein et al., 2011).

We next turn to the main goal of the present study, namely, characterizing the neural substrates of subjects' strategic control over the degree to which WM cues affected the allocation of visual attention.

\section{Source regions of cognitive control over WM biases on attentional selection}

To isolate the source of control signals associated with observer's foreknowledge about WM validity for search behavior, we analyzed activity associated with cue-only trials (those not followed by search displays) in the different blocks (Ollinger et al., 2001). By contrasting cue-related activity in $100 \%$ valid and invalid blocks with that obtained in 50/50 blocks, we could delineate control signals associated with the enhancement or inhibition of the influence of WM on attention, respectively. Figure 3 shows the signal change in the different high predictability conditions relative to the 50/50 baseline. Specifically, cue-related activity associated with $100 \%$ valid blocks (relative to 50/50 conditions) was associated with increased activity in a cluster around the left intraparietal sulcus and angular gyrus (BA40) (MNI: - 36, -48, 38, 1455 voxels), as well as a cluster in visual cortex around the lingual gyrus (BA18) (MNI: 14, $-84,-12,1302$ voxels). This particular effect is shown in Figure $3, A$ and $B$, in green. By contrast, cue-related activity 
A

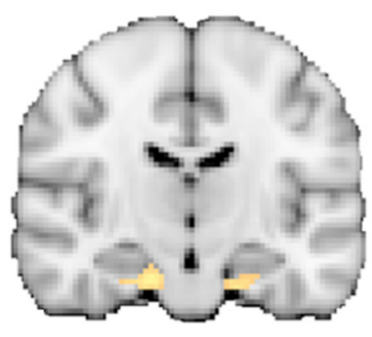

B

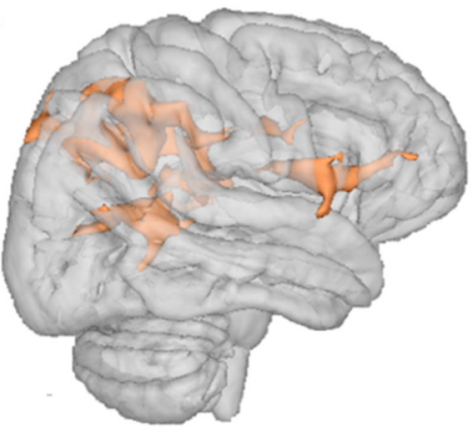

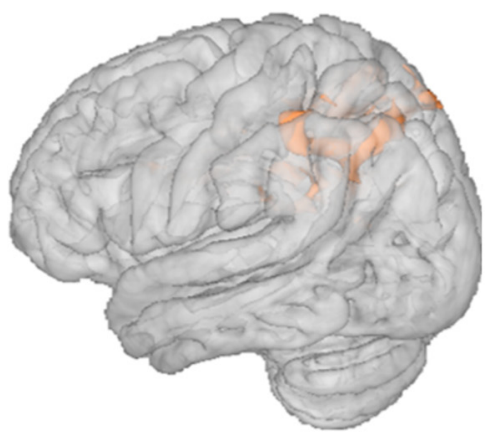

Figure 2. Neural substrates of WM validity effects on visual selection. $A$, Parahippocampal areas are more active when WM cue is valid relative to invalid for search across both high and low WM predictability conditions. $B$, Frontoparietal regions are more active when the WM cue is invalid relative to valid for search. Activated voxel clusters in a whole-brain analysis $(Z>2.3, p<0.05$, corrected).

A

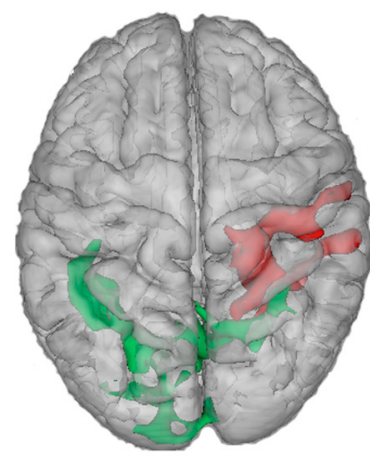

B

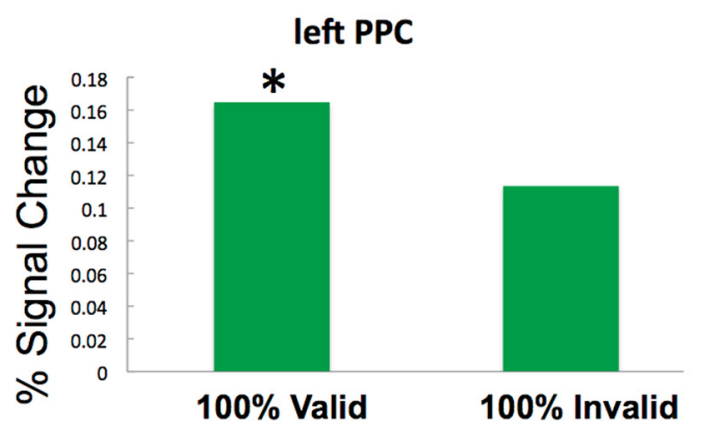

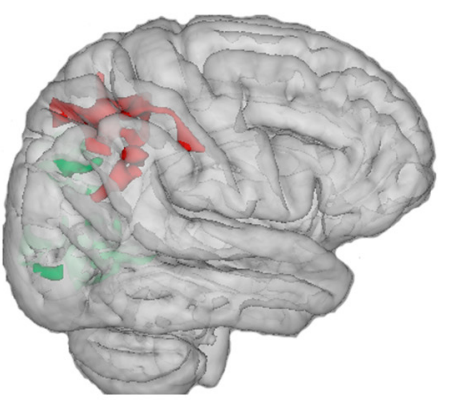

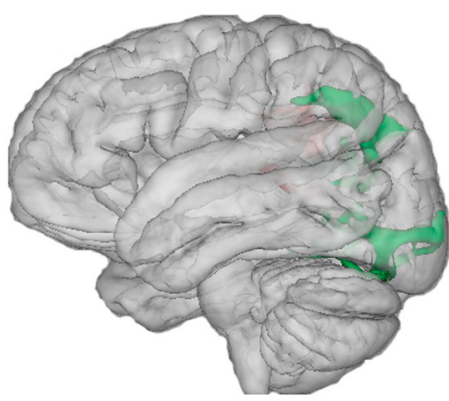

C right PPC

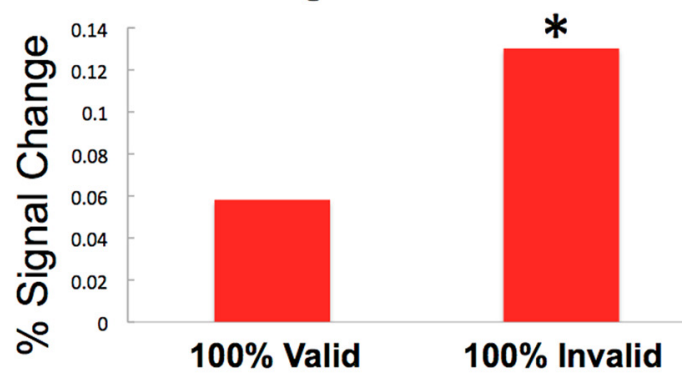

Figure 3. Neural substrates of anticipatory control over WM-attention interaction. $A$, In green are the areas that are more active during cue-only trials when observers have foreknowledge that the WM cue is a valid predictor of the search target. In red are regions showing increased activity during cue-only trials when the WM content reliably predicted an invalid distracter in search relative to when there was no such foreknowledge. Clusters of activity are derived relative to the $50 / 50$ baseline. $\boldsymbol{B}$, Signal change $(\%)$ is plotted for the peak active cluster (MNI: $-36,-48,38)$ of the left PPC for cue-related activity in $100 \%$ valid blocks and 100\% invalid blocks (effects are displayed relative to the $50 / 50$ unpredictable baseline; $Z>1.96, p<0.05$, corrected). C, Signal change (\%) is plotted for the peak active cluster (MNI $40-483$ ) of the right PPC for cue-related activity in 100\% valid blocks and $100 \%$ invalid blocks (effects are displayed relative to the $50 / 50$ unpredictable baseline).

associated with $100 \%$ invalid blocks (relative to $50 / 50$ conditions) was observed around the right intraparietal sulcus (BA39) (MNI: 40, $-48,30,1538$ voxels) extending into the right superior parietal lobe and the postcentral gyrus. This particular effect is shown in Figure 3, $A$ and $C$, in red. We also found a right PPC cluster (BA7) (MNI: 22, $-52,54,1132$ voxels) that was generally more active in the predictable conditions (either valid or invalid) relative to the 50/50 conditions that overlapped with the regions depicted in Figure $3 B$ and also extended more medially into the precuneus cortex (MNI: 0, - 56, 40; data not shown).

These results indicate the presence of preparatory signals in the PPC based on foreknowledge of WM validity for either enhancing or inhibiting the coupling between WM content and attention.

We performed further exploratory analyses by extracting the contrast of parameter estimates of the BOLD response for the above conditions using $3 \mathrm{~mm}$ spheres around the cluster peak of the predictable $>$ unpredictable condition contrasts for both left and right PPCs. A $2 \times 2$ ANOVA with PPC (left, right) and cue predictability context (target, distracter) showed an interaction between those factors $\left(F_{(1,20)}=8.21, p<0.01\right)$. No main effects were observed (lowest, $p=0.255$ ). Post hoc $t$ tests showed that engagement of the PPC during cue-only trials when the WM content predicted the search target was stronger in the left than in the right PPC $\left(t_{(20)}=2.83, p=0.01\right)$ and that the right PPC was more active when the WM content predicted a distracter relative to when it predicted the search target $\left(t_{(20)}=2.2\right.$, $p=0.04)$. These results raise the intriguing possibility of a lateralization in the PPC according to whether subjects enhanced or suppressed the influence of the WM cue on attention. We note, however, that this pattern of results was not 
borne out by a whole-brain (corrected) level of analyses that revealed no differential PPC activations between 100\% valid versus $100 \%$ invalid contrasts.

\section{Regions of cognitive control over WM biases on attentional selection during search}

We next assessed the effects of cognitive control resulting from foreknowledge of WM cue validity on search-related neural activity by analyzing trials that included a search display. (Note that we already reported the orthogonal main effect analysis of the cue validity factor above.) A contrast assessing the main effect of predictability by comparing search trials with WM validity foreknowledge, namely the $100 \%$ valid and the $100 \%$ invalid blocks with the unpredictable 50/50 valid and invalid conditions, revealed that generally knowing the cue was associated with the sought after target or with a distracter activated a network involving the anterior and posterior right hippocampus (BA30; MNI: $22,-22,-16,921$ voxels) extending into right orbitofrontal cortex (MNI: 24,12, -16). Figure $4 A$ depicts the pattern of results. Another cluster covered the retrosplenial cortex (BAs 26 and 30), posterior cingulate (BA23; MNI: 2, -42, 24; 713 voxels), and the visual cortex around the lingual gyrus (BA17; MNI: 16, $-56,12$, 921 voxels). Thus, responses in these regions appear to reflect the consequences of attentional control signals stemming from WM foreknowledge, enhancing activity under conditions that maximally predict whether the WM content will be associated with a target or a distracter.

We aimed to determine which of these areas (if any) may be most relevant to the behavioral effect, namely, improvement in search by foreknowledge about WM validity. Therefore, fMRIbehavior correlations were conducted using the subject-specific contrast of parameter estimates extracted from those a priori ROIs from the group-based analyses. We computed the Pearson correlation between the signal change associated with the effect of foreknowledge about WM validity within the hippocampus, posterior cingulate cortex (PCC), the orbitofrontal cortex (OFC) the lingual gyrus (LG), and the individual behavioral performance, namely, the effect of foreknowledge of WM validity on search performance [(RT Valid 50/50 - RT Valid 100\%) + (RT Invalid $50 / 50$ - RT Invalid 100\%)/2]. Signal change was extracted from a $3 \mathrm{~mm}$ sphere centered at the anatomical coordinates of the regions outlined above. The results showed that neither the PCC or the OFC nor the LG responses correlated with the behavioral score (PCC: $r=0.186, p=0.447$; right OFC: $r=-0.123, p=$ 0.617; LG: $r=0.123, p=0.615)$. The hippocampal response, however, correlated with intersubject variation in the effect of foreknowledge of WM validity on behavior $(r=0.55, p<0.014$; Fig. $4 B$ ). We replicated this result using an anatomical $3 \mathrm{~mm}$ ROI centered on of the hippocampus proper (MNI: $28,-26,-12$ ) according to the Harvard-Oxford anatomical probabilistic atlas part of FSL ( $r=0.66, p<0.002$, two tailed), thus indicating that the modulation of hippocampal activity by foreknowledge about WM cue validity was of functional relevance to behavior. Therefore, using these a priori ROIs, only the hippocampus showed such a correlation, suggesting a selective role.

We further explored the possibility that other regions that were not a priori candidates for this correlation (because they did not show up in our previous analyses) might nevertheless show a close relation to this behavioral effect. We therefore conducted a whole-brain analysis with our behavioral covariate, which was modeled at within-subject, fixed-effects analyses across fMRI runs. The whole-brain covariate analyses showed a cluster in the posterior cingulate cortex (BA23, MNI: $-2,-48,32)$ that cova- ried positively with across run variation in the effect of foreknowledge of WM validity on behavior $(Z>2.3, p<0.05$, corrected). This PPC cluster (see Fig. $4 A$ in red, at right) overlapped with the posterior cingulate cluster that was sensitive to WM validity foreknowledge. At a more relaxed statistical threshold, we again observed voxels in the hippocampus (data not shown).

Taken together, these results suggest that hippocampus and the posterior cingulate correlate with the behavioral expression of cognitive control over WM biases, but the hippocampus correlated with intersubject variability while the posterior cingulate explained within-subject variation in behavior across fMRI runs.

In addition to this main effect of cognitive control by foreknowledge of WM validity, we also tested whether the neural substrates of this cognitive control effect varied as a function of the particular validity status of the WM cue in the search task by assessing the predictability by validity interaction effect. In other words, we tested for regions that were selectively involved in inhibiting (in invalid cases) or enhancing (in valid cases) the effects of the WM cue during search as a function of validity foreknowledge. The results revealed that WM validity responses in visual cortex (BA18) (MNI: $-22,-100,-14 ; 1553$ voxels) and superior temporal cortex (BA21) (MNI: $-64,-18,-14 ; 1266$ voxels) were selectively modulated by predictability of valid trials (Fig. 4C). There were no regions above threshold that showed increased in-validity effects during search at the highest level of predictability.

In sum, these results document the involvement of the PPC in generating preparatory signals linked to foreknowledge about WM validity before the onset of the search displays. An additional network of regions involving the medial temporal lobe, including the hippocampus proper and regions of the posterior cingulate/ retrosplenial cortex, was associated with the cognitive control of WM biases during search itself.

\section{Discussion}

Behavioral performance revealed that search was faster on valid relative to invalid WM cue trials. Critically, knowing about the validity status of WM content optimized search efficiency: observers appeared to inhibit the WM content from guiding attention on predictable trials with invalid cueing and to enhance WM guidance of attention when the WM cue reliably coincided with the search target. This pattern of results suggests that WM biases can be controlled in a top-down manner by foreknowledge about the validity of the WM content (Han and Kim, 2009; Carlisle and Woodman, 2011). We also note that recent behavioral evidence using the same paradigm as employed here showed that predictable invalid blocks can still lead to slower performance relative to a neutral baseline block without memory matching items (Kiyonaga et al., 2012), suggesting that cognitive control can attenuate but not fully overcome the WM bias. Moreover, the latter study showed that these control processes modulate access to the memory representation itself, with retrieval of the WM content in surprise recognition tests being slowest in $100 \%$ invalid task blocks where the memorandum was presumably strategically inhibited; critically, recognition accuracy was similar in the $100 \%$ invalid and $100 \%$ valid task blocks as we found here, suggesting that $100 \%$ invalid conditions do not degrade the quality of the memory trace but its accessibility. Taken together, these results are in line with evidence for coexistence of automatic and strategic components in the guidance of attention by WM representations (Han and Kim, 2009; Carlisle and Woodman, 2011).

In the imaging data, we found evidence that cognitive control over WM biases involves mechanisms that operate during the 
A
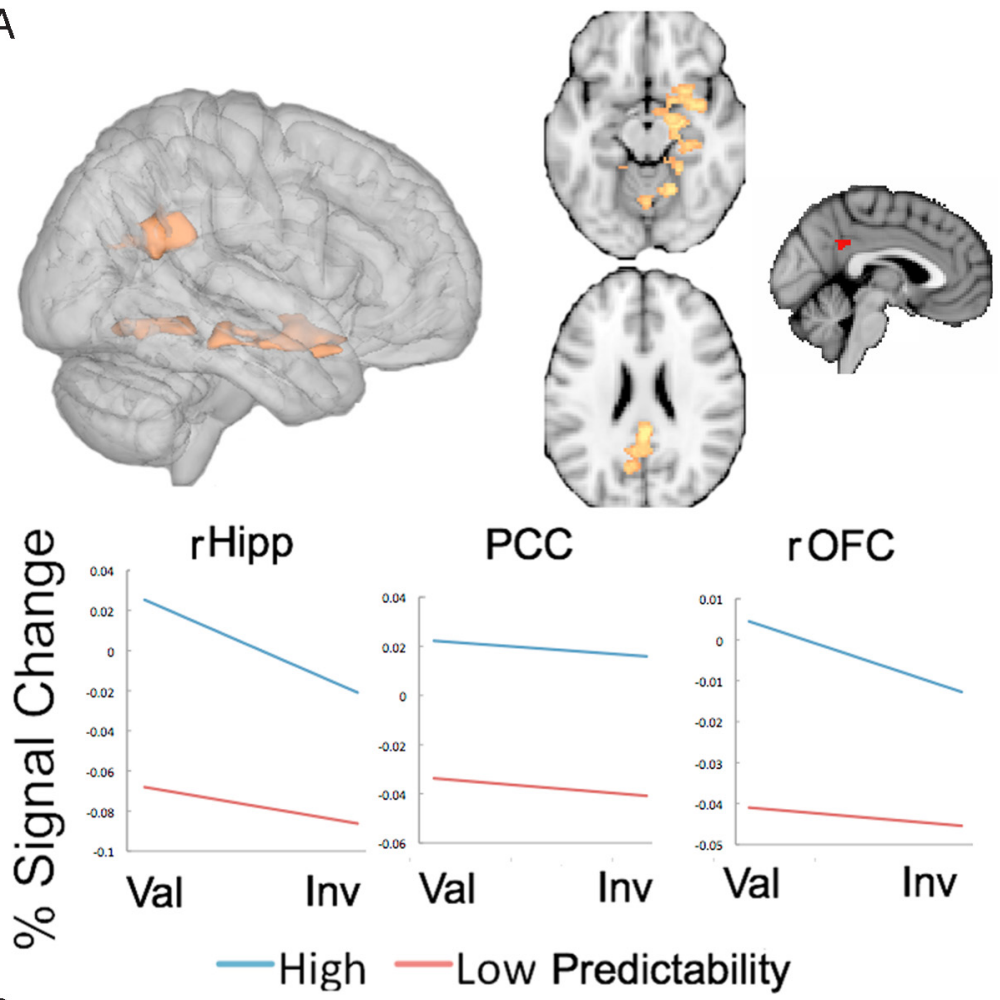

PCC

rOFC

B

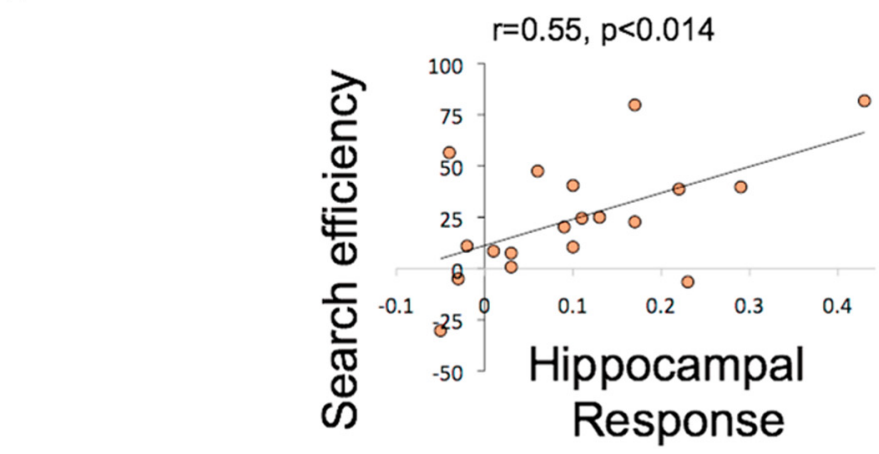

C
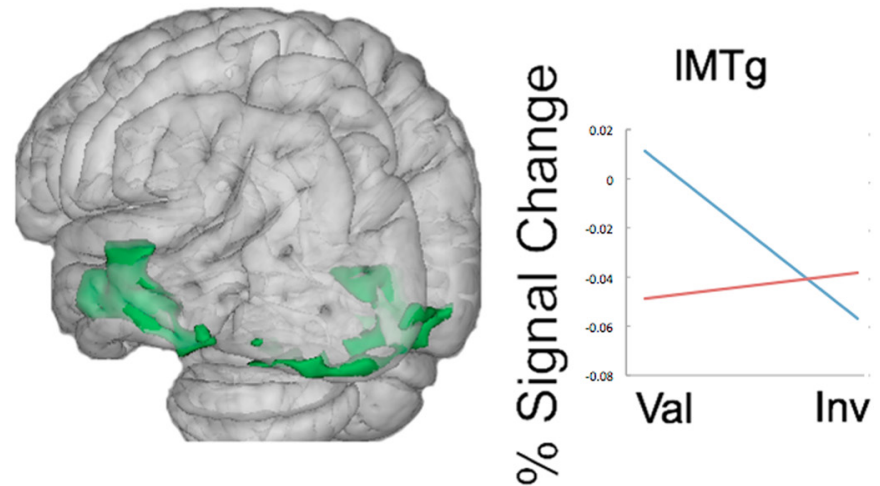

Figure 4. Neural effects of control over WM-attention interaction during visual search. $A$, In yellow are activated voxel clusters in a whole-brain analysis ( $Z>2.3, p<0.05$, corrected) of cue plus search periods showing areas that are more active when cues predictably coincided with targets or distracters than when cue-target relations were unpredictable (100\% valid/invalid $>50 \%$ valid/invalid blocks) (rHipp, Right hippocampus; Val, Valid; Inv, invalid). In red are voxels that covaried with within-subject variability in the behavioral effect of foreknowledge about WM validity ( $Z>2.3, p<0.05$, corrected). PCC, Posterior cingulate cortex; rOFC, right orbitofrontal cortex). B, Correlation between hippocampal response enhancement by predictable cues (see $\boldsymbol{A}$ ) and behavioral search efficiency due to foreknowledge of WM validity (for details, see Results). $\boldsymbol{C}$, Voxel clusters that were selectively more activated during search in the predictably valid cue condition than in the predictably invalid cue condition. Percent signal change is plotted for the peak of the cluster on the left middle temporal gyrus (IMTg) $(Z>1.96, p<0.05$, corrected). 
memory delay maintenance period (in anticipation of search) and also during the search period itself. A first critical finding is that the PPC is involved in generating preparatory control signals during the cue-delay period stemming from WM validity foreknowledge before the onset of the search. These preparatory control signals originating in the PPC exhibited some evidence for hemispheric lateralization, whereby activity predominated in the left PPC when WM contents were known to be valid, whereas WM contents known to be invalid for search were associated with activity in the right PPC. This evidence of lateralization in the PPC signal is interesting, because extant data suggest that engagement of dorsal frontoparietal networks in attentional control is bilateral (Shulman et al., 2010). Lateralization of dorsal PPC function has, however, been observed in bottom-up, saliencybased selection tasks depending on whether the salient item needs to be selected or ignored (Mevorach et al., 2006). However, our evidence for PPC lateralization in the control of WM biases is only preliminary, and further work is needed to address this interesting possibility in more depth.

Prior research on spatial attention (Grent-'t-Jong and Woldorff, 2007; Bressler et al., 2008; Sylvester et al., 2009) has delineated how preparatory neural activity for expected relevant target locations is implemented through an interplay between frontal cortex, PPC, and visual regions. The PPC is also involved in the integration of relevant feature- and space-based cues to optimize the deployment of attention in visual search (Egner et al., 2008). The current findings expand on the role of the PPC in attentional control by documenting its involvement in preparatory control of irrelevant WM biases, that is, in the apparent suppression of WM influences on attention. In addition to computing target-biasing signals (Shulman et al., 2002), our evidence suggests that the PPC may also play a role in generating a "template for rejection" (Woodman and Luck, 2007) that may help to prevent attentional capture by irrelevant information held in memory. Previous evidence for a role of the PPC in inhibitory processing comes from visual marking studies in which the preexposure to irrelevant item locations is immediately followed by a set of new items containing the critical search target. Search performance benefits from pre-exposure to the distracters relative to when all sets of items appear at once. Regions of the superior parietal cortex (BA7) have been linked with the parsing of the pre-exposed irrelevant locations (Pollmann et al., 2003; Olivers et al., 2005).

We note that parietal regions were not consistently activated in previous studies assessing biases of attention by the contents of WM (Soto et al., 2007, 2011, 2012a, 2012b; Grecucci et al., 2010); however these studies used nonpredictive WM cues that may not have maximized the engagement of anticipatory cognitive control processes. Notably, superior dorsolateral prefrontal regions did not appear to be associated with the control of WM biases in the current study, as could have been anticipated from well established evidence for a dorsal frontoparietal engagement in topdown attentional control (Corbetta and Shulman, 2002). Instead, our data indicate that cognitive control of WM biases may recruit a different pathway involving the PPC, the posterior cingulate, and medial temporal regions (see below).

The role of temporal structures in WM-guidance is associated with both WM validity effects and with their strategic cognitive control. First, regions around the anterior parahippocampal gyrus displayed enhanced activity when WM contents overlapped with the sought-after target relative to when they were invalid for search. These results are likely to reflect the bias of attention in the search through WM. This is concordant with single-unit work from Chelazzi and colleagues (Chelazzi et al., 1993 , 1998) that has shown enhanced neuronal responses around the rhinal sulci for remembered items that had to be selected for a response, and similar single unit responses have been reported in perihirnal cortex (Lehky and Tanaka, 2007). Activity in the parahippocampal gyrus has also been observed in functional MRI studies in humans assessing WM biases of visual attention (Soto et al., 2007; Grecucci et al., 2010) and in visual perceptual tasks (Murray and Richmond, 2001; Buckley and Gaffan, 2006; O’Neil et al., 2009).

A second type of response in the medial-temporal lobe was associated with the strategic control over WM biases. Notably, the magnitude of the hippocampal response here predicted the efficiency of attentional selection based on foreknowledge of WM validity for search. Responses in the right anterior and posterior hippocampus proper extended into the right orbitofrontal cortex, the posterior cingulate (which also displayed a correlation with the behavioral effect), and also retrosplenial and precuneus cortex. Anatomical studies in primates indicate the existence of a parieto-middle temporal pathway stemming from regions in the inferior PPC that project to hippocampal and parahippocampal regions either directly or via the posterior cingulate and retrosplenial cortices (Vann et al., 2009; Kravitz et al., 2011). A similar network is present in humans (Margulies et al., 2009). The functional role of this circuitry has been mainly associated with spatial processing (i.e., navigation) and memory (Aguirre and D'Esposito, 1999; Grön et al., 2000; Buckner et al., 2008). Interestingly, all of the regions comprising this parieto-medial temporal pathway in the present study were linked to the guidance of visual selection by memory representations.

There is fast-growing evidence of hippocampal involvement in WM processing, specifically in maintenance operations (Ranganath and D'Esposito, 2001; Axmacher et al., 2007, 2010; Hartley et al., 2007; Poch et al., 2011); but see (Jeneson and Squire, 2012). In the current study, hippocampal responses did not merely reflect the maintenance of memory cues, but the behavioral "validity" and the task-set associated with the cues being maintained. It appears difficult to argue that hippocampal engagement in our task could reflect contributions from long-term memory (Jeneson and Squire, 2012), considering that a single item had to be maintained for a $2 \mathrm{~s}$ delay. Thus, the data presented here suggest that the hippocampus, like surrounding regions of the medial temporal lobe, may have an important role in visual processing (Lee et al., 2005a; Devlin and Price, 2007) under conditions that do not depend on long-tem memory and are more akin to attentional selection guided by the contents of WM, similar to hippocampal involvement in guiding spatial attention based on long-term memory representations (Summerfield et al., 2006; Stokes et al., 2012).

The question then arises as to the precise contribution of the hippocampus to the interaction between WM and visual selective attention. Along with parahippocampal cortices, the hippocampus has been implicated in visual identification tasks, although the hippocampus may support more complex representations in this regard (Lee et al., 2005a,2005b, 2006, 2008). In the context of our experiment, we suggest that the hippocampus may form a representation that incorporates knowledge about the relevance/ predictability of the visual cues, which may then be used by other neural regions to control selection, such as the anterior parahippocampal cortex (Chelazzi et al., 1993, 1998).

Recent research suggests that WM contents may be flexibly partitioned according to their relevance for behavior, such that goal-irrelevant WM items may be relegated to an accessory state 
outside of the focus of internal attention (Oberauer, 2002; Olivers et al., 2011), reducing their interference with relevant target selection. A role of the hippocampus in inhibiting information held in memory has been put forward (Anderson et al., 2004), and we here suggest that the hippocampus forms part of a parieto-medial temporal pathway that may support the "switching" of the state of memory representations for the control of goal-directed attention.

\section{References}

Aguirre GK, D’Esposito M (1999) Topographical disorientation: a synthesis and taxonomy. Brain 122:1613-1628. CrossRef Medline

Anderson MC, Ochsner KN, Kuhl B, Cooper J, Robertson E, Gabrieli SW, Glover GH, Gabrieli JD (2004) Neural systems underlying the suppression of unwanted memories. Science 303:232-235. CrossRef Medline

Axmacher N, Mormann F, Fernández G, Cohen MX, Elger CE, Fell J (2007) Sustained neural activity patterns during working memory in the human medial temporal lobe. J Neurosci 27:7807-7816. CrossRef Medline

Axmacher N, Henseler MM, Jensen O, Weinreich I, Elger CE, Fell J (2010) Cross-frequency coupling supports multi-item working memory in the human hippocampus. Proc Natl Acad Sci USA 107:3228-3233. CrossRef Medline

Bressler SL, Tang W, Sylvester CM, Shulman GL, Corbetta M (2008) Topdown control of human visual cortex by frontal and parietal cortex in anticipatory visual spatial attention. J Neurosci 28:10056-10061. CrossRef Medline

Buckley MJ, Gaffan D (2006) Perirhinal cortical contributions to object perception. Trends Cogn Sci 10:100-107. CrossRef Medline

Buckner RL, Andrews-Hanna JR, Schacter DL (2008) The brain's default network: anatomy, function, and relevance to disease. Ann NY Acad Sci 1124:1-38. CrossRef Medline

Carlisle NB, Woodman GF (2011) Automatic and strategic effects in the guidance of attention by working memory representations. Acta Psychol (Amst) 137:217-225. CrossRef Medline

Chelazzi L, Miller EK, Duncan J, Desimone R (1993) A neural basis for visual search in inferior temporal cortex. Nature 363:345-347. CrossRef Medline

Chelazzi L, Duncan J, Miller EK, Desimone R (1998) Responses of neurons in inferior temporal cortex during memory-guided visual search. J Neurophysiol 80:2918-2940. Medline

Corbetta M, Shulman GL (2002) Control of goal-directed and stimulusdriven attention in the brain. Nat Rev Neurosci 3:201-215. CrossRef Medline

Devlin JT, Price CJ (2007) Perirhinal contributions to human visual perception. Curr Biol 17:1484-1488. CrossRef Medline

Downing PE, Dodds CM (2004) Competition in visual working memory for control of search. Vis Cogn 11:689-703. CrossRef

Dudukovic NM, Preston AR, Archie JJ, Glover GH, Wagner AD (2011) High-resolution fMRI reveals match enhancement and attentional modulation in the human medial temporal lobe. J Cogn Neurosci 23:670-682. CrossRef Medline

Duncan K, Curtis C, Davachi L (2009) Distinct memory signatures in the hippocampus: intentional States distinguish match and mismatch enhancement signals. J Neurosci 29:131-139. CrossRef Medline

Egner T, Monti JM, Trittschuh EH, Wieneke CA, Hirsch J, Mesulam MM (2008) Neural integration of top-down spatial and feature-based information in visual search. J Neurosci 28:6141-6151. CrossRef Medline

Grecucci A, Soto D, Rumiati RI, Humphreys GW, Rotshtein P (2010) The interrelations between verbal working memory and visual selection of emotional faces. J Cogn Neurosci 22:1189-1200. CrossRef Medline

Greene CM, Soto D (2012) Neural repetition effects in the medial temporal lobe complex are modulated by previous encoding experience. PLoS One 7:e40870. CrossRef Medline

Grent-'t-Jong T, Woldorff MG (2007) Timing and sequence of brain activity in top-down control of visual-spatial attention. PLoS Biol 5:e12. CrossRef Medline

Grön G, Wunderlich AP, Spitzer M, Tomczak R, Riepe MW (2000) Brain activation during human navigation: gender-different neural networks as substrate of performance. Nat Neurosci 3:404-408. CrossRef Medline

Han SW, Kim MS (2009) Do the contents of working memory capture at- tention? Yes, but cognitive control matters. J Exp Psychol Hum Percept Perform 35:1292-1302. CrossRef Medline

Hartley T, Bird CM, Chan D, Cipolotti L, Husain M, Vargha-Khadem F, Burgess N (2007) The hippocampus is required for short-term topographical memory in humans. Hippocampus 17:34-48. CrossRef Medline

Houtkamp R, Roelfsema PR (2006) The effect of items in working memory on the deployment of attention and the eyes during visual search. J Exp Psychol Hum Percept Perform 32:423-442. CrossRef Medline

Jeneson A, Squire LR (2012) Working memory, long-term memory, and medial temporal lobe function. Learn Mem 19:15-25. CrossRef Medline

Jenkinson M, Bannister P, Brady M, Smith S (2002) Improved optimization for the robust and accurate linear registration and motion correction of brain images. Neuroimage 17:825-841. CrossRef Medline

Kiyonaga A, Egner T, Soto D (2012) Cognitive control over working memory biases of selection. Psychon Bull Rev 19:639-646. CrossRef Medline

Kravitz DJ, Saleem KS, Baker CI, Mishkin M (2011) A new neural framework for visuospatial processing. Nat Rev Neurosci 12:217-230. CrossRef Medline

Lee AC, Bussey TJ, Murray EA, Saksida LM, Epstein RA, Kapur N, Hodges JR, Graham KS (2005a) Perceptual deficits in amnesia: challenging the medial temporal lobe 'mnemonic' view. Neuropsychologia 43:1-11. CrossRef Medline

Lee AC, Buckley MJ, Pegman SJ, Spiers H, Scahill VL, Gaffan D, Bussey TJ, Davies RR, Kapur N, Hodges JR, Graham KS (2005b) Specialization in the medial temporal lobe for processing of objects and scenes. Hippocampus 15:782-797. CrossRef Medline

Lee AC, Buckley MJ, Gaffan D, Emery T, Hodges JR, Graham KS (2006) Differentiating the roles of the hippocampus and perirhinal cortex in processes beyond long-term declarative memory: a double dissociation in dementia. J Neurosci 26:5198-5203. CrossRef Medline

Lee AC, Scahill VL, Graham KS (2008) Activating the medial temporal lobe during oddity judgment for faces and scenes. Cereb Cortex 18:683-696. CrossRef Medline

Lehky SR, Tanaka K (2007) Enhancement of object representations in primate perirhinal cortex during a visual working-memory task. J Neurophysiol 97:1298-1310. CrossRef Medline

Margulies DS, Vincent JL, Kelly C, Lohmann G, Uddin LQ, Biswal BB, Villringer A, Castellanos FX, Milham MP, Petrides M (2009) Precuneus shares intrinsic functional architecture in humans and monkeys. Proc Natl Acad Sci U S A 106:20069-20074. CrossRef Medline

Mevorach C, Humphreys GW, Shalev L (2006) Opposite biases in saliencebased selection for the left and right posterior parietal cortex. Nat Neurosci 9:740-742. CrossRef Medline

Murray EA, Richmond BJ (2001) Role of perirhinal cortex in object perception, memory, and associations. Curr Opin Neurobiol 11:188-193. CrossRef Medline

Oberauer K (2002) Access to information in working memory: exploring the focus of attention. J Exp Psychol Learn Mem Cogn 28:411-421. CrossRef Medline

Olivers CN, Smith S, Matthews P, Humphreys GW (2005) Prioritizing new over old: an fMRI study of the preview search task. Hum Brain Mapp 24:69-78. CrossRef Medline

Olivers CN, Peters J, Houtkamp R, Roelfsema PR (2011) Different states in visual working memory: when it guides attention and when it does not. Trends Cogn Sci 15:327-334. CrossRef Medline

Ollinger JM, Corbetta M, Shulman GL (2001) Separating processes within a trial in event-related functional MRI. Neuroimage 13:218-229. CrossRef Medline

O’Neil EB, Cate AD, Köhler S (2009) Perirhinal cortex contributes to accuracy in recognition memory and perceptual discriminations. J Neurosci 29:8329-8334. CrossRef Medline

Peters JC, Goebel R, Roelfsema PR (2009) Remembered but unused: the accessory items in working memory that do not guide attention. J Cogn Neurosci 21:1081-1091. CrossRef Medline

Poch C, Fuentemilla L, Barnes GR, Düzel E (2011) Hippocampal thetaphase modulation of replay correlates with configural-relational shortterm memory performance. J Neurosci 31:7038-7042. CrossRef Medline

Pollmann S, Weidner R, Humphreys GW, Olivers CN, Müller K, Lohmann G, Wiggins CJ, Watson DG (2003) Separating distractor rejection and target detection in posterior parietal cortex-an event-related fMRI study of visual marking. Neuroimage 18:310-323. CrossRef Medline 
Ranganath C, D’Esposito M (2001) Medial temporal lobe activity associated with active maintenance of novel information. Neuron 31:865-873. CrossRef Medline

Rotshtein P, Soto D, Grecucci A, Geng JJ, Humphreys GW (2011) The role of the pulvinar in resolving competition between memory and visual selection: a functional connectivity study. Neuropsychologia 49:15441552. CrossRef Medline

Schenkluhn B, Ruff CC, Heinen K, Chambers CD (2008) Parietal stimulation decouples spatial and feature-based attention. J Neurosci 28:1110611110. CrossRef Medline

Shulman GL, Tansy AP, Kincade M, Petersen SE, McAvoy MP, Corbetta M (2002) Reactivation of networks involved in preparatory states. Cereb Cortex 12:590-600. CrossRef Medline

Shulman GL, Pope DL, Astafiev SV, McAvoy MP, Snyder AZ, Corbetta M (2010) Right hemisphere dominance during spatial selective attention and target detection occurs outside the dorsal frontoparietal network. J Neurosci 30:3640-3651. CrossRef Medline

Smith SM (2002) Fast robust automated brain extraction. Hum Brain Mapp 17:143-155. CrossRef Medline

Soto D, Heinke D, Humphreys GW, Blanco MJ (2005) Early, involuntary top-down guidance of attention from working memory. J Exp Psychol Hum Percept Perform 31:248-261. CrossRef Medline

Soto D, Humphreys GW, Rotshtein P (2007) Dissociating the neural mechanisms of memory-based guidance of visual selection. Proc Natl Acad Sci U S A 104:17186-17191. CrossRef Medline

Soto D, Hodsoll J, Rotshtein P, Humphreys GW (2008) Automatic guidance of attention from working memory. Trends Cogn Sci 12:342-348. CrossRef Medline

Soto D, Mok AY, McRobbie D, Quest R, Waldman A, Rotshtein P (2011) Biasing visual selection: functional neuroimaging of the interplay between spatial cueing and feature memory guidance. Neuropsychologia 49:1537-1543. CrossRef Medline
Soto D, Rotshtein P, Hodsoll J, Mevorach C, Humphreys GW (2012a) Common and distinct neural regions for the guidance of selection by visuoverbal information held in memory: converging evidence from fMRI and rTMS. Hum Brain Mapp 33:105-120. CrossRef Medline

Soto D, Greene CM, Chaudhary A, Rotshtein P (2012b) Competition in working memory reduces frontal guidance of visual selection. Cereb Cortex 22:1159-1169. CrossRef Medline

Stokes MG, Atherton K, Patai EZ, Nobre AC (2012) Long-term memory prepares neural activity for perception. Proc Natl Acad Sci U S A 109: E360-E367. CrossRef Medline

Strumpf H, Mangun GR, Boehler CN, Stoppel C, Schoenfeld MA, Heinze HJ, Hopf JM (2012) The role of the pulvinar in distractor processing and visual search. Hum Brain Mapp. Advance online publication. Retrieved April 4, 2012. CrossRef Medline

Summerfield JJ, Lepsien J, Gitelman DR, Mesulam MM, Nobre AC (2006) Orienting attention based on long-term memory experience. Neuron 49: 905-916. CrossRef Medline

Sylvester CM, Shulman GL, Jack AI, Corbetta M (2009) Anticipatory and stimulus-evoked blood oxygenation level-dependent modulations related to spatial attention reflect a common additive signal. J Neurosci 29:10671-10682. CrossRef Medline

Toth LJ, Assad JA (2002) Dynamic coding of behaviourally relevant stimuli in parietal cortex. Nature 415:165-168. CrossRef Medline

Vann SD, Aggleton JP, Maguire EA (2009) What does the retrosplenial cortex do? Nat Rev Neurosci 10:792-802. CrossRef Medline

Woodman GF, Luck SJ (2007) Do the contents of visual working memory automatically influence attentional selection during visual search? J Exp Psychol Hum Percept Perform 33:363-377. CrossRef Medline

Woolrich MW, Ripley BD, Brady M, Smith SM (2001) Temporal autocorrelation in univariate linear modeling of FMRI data. Neuroimage 14: 1370-1386. CrossRef Medline 